\title{
Extraluminal location of a Foley catheter balloon
}

\author{
CL Cho *, Wayne KW Chan, Ringo WH Chu, IC Law
}

Hong Kong Med J 2017;23:207.e1-2

DOI: 10.12809/hkmj164938

Indwelling urinary catheters are generally safe but may be associated with complications. Although intraperitoneal or extraperitoneal perforation is rare, the condition can be life-threatening. ${ }^{1}$ Abdominopelvic computed tomography (CT) is commonly performed in hospitalised patients. In many cases the urinary bladder is catheterised and included in the scan; CT scan is a reliable method to evaluate many pathologies of the urinary bladder. ${ }^{2}$ The apparent extraluminal position of a Foley catheter tip or balloon can be misleading, however. ${ }^{3}$ We present a case in which a Foley catheter balloon was inflated in a bladder diverticulum mimicking an extraluminal location on a CT scan.

\section{Case}

A 68-year-old man was admitted with abdominal distension and suprapubic pain in April 2016. He was a visitor to Hong Kong and had a history of recurrent acute urinary retention. A urethral Foley catheter had been inserted in his home country a week before presentation and he travelled to Hong Kong with the catheter in situ. A urological assessment was scheduled on his return home. He had a history of open left nephrectomy performed over 20 years ago

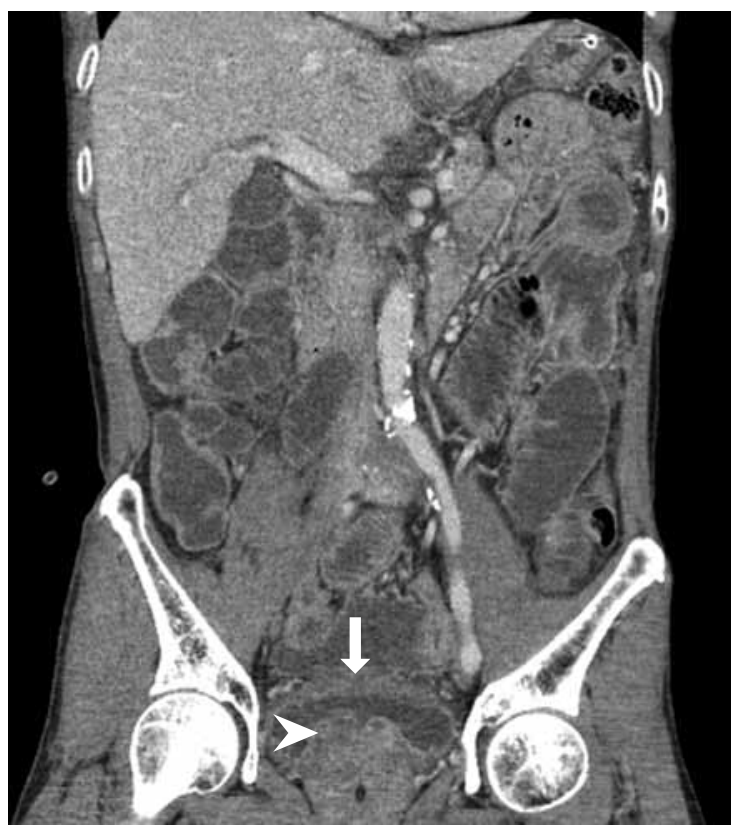

FIG I. Coronal computed tomographic scan demonstrating the thickened urinary bladder wall (arrow) and large intravesical prostatic protrusion (arrowhead) for urinary stone disease but otherwise had good medical history.
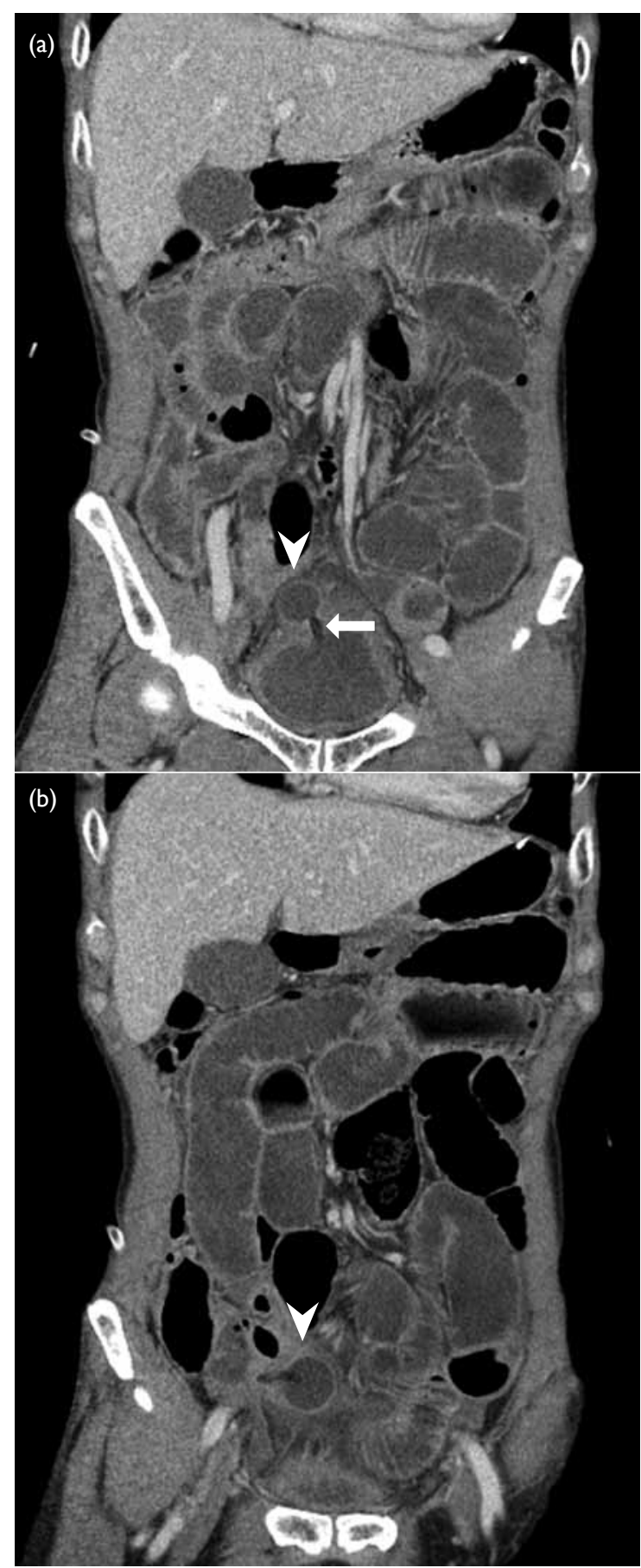

FIG 2. Axial computed tomographic scan of the pelvis demonstrating (a) the Foley catheter through the thickened urinary bladder wall (arrow) and extraluminal location of balloon (arrowhead); and (b) the extraluminal location of balloon and Foley catheter tip (arrowhead) 
On presentation he was afebrile and normotensive. The abdomen was grossly distended with suprapubic tenderness and a general surgeon was consulted. Digital rectal examination revealed a grossly enlarged non-suspicious prostate. Clear urine and good urine outputs from the Foley catheter were noted. Laboratory tests showed an elevated white blood cell count of $14.5 \times 10^{9} / \mathrm{L}$ and normal creatinine level of $125 \mu \mathrm{mol} / \mathrm{L}$. A nasogastric tube was inserted with a working diagnosis of intestinal obstruction. An urgent contrast CT scan revealed grossly dilated small bowel loops with free fluid in the pelvis and paracolic gutters. The wall of the urinary bladder was thickened with a large prostate and intravesical prostatic protrusion (Fig 1). The tip of the Foley catheter appeared to be at an extravesical location (Fig 2).

A urological opinion was sought and the patient underwent exploratory laparotomy. Intraoperatively, the tip of the Foley catheter and balloon were noted inside a large 5 -cm bladder diverticulum at the dome of the urinary bladder. There was a $5-\mathrm{mm}$ concealed perforation at the bladder diverticulum with surrounding dusky tissue covered by slough. Bladder diverticulectomy was performed. The urinary bladder was closed in a two-layer fashion and confirmed water-tight. No bowel injury was evident and an extensive washout was performed. A pelvic drain and 18F Foley catheter were inserted.

Postoperatively, the patient progressed well. Diet was resumed on postoperative day 3 and the drain was removed. There were no wound complications and the patient was fit for discharge on day 5 . He returned to his home country with the Foley catheter in situ. We advised maintenance of bladder drainage until surgery for benign prostate hyperplasia could be performed.

This case concurs with a previous report that extraluminal location of a Foley catheter balloon on imaging can be misleading. ${ }^{3}$ Exploratory laparotomy based on the radiological findings alone may not be appropriate, especially when the clinical suspicion of bladder perforation is low. Further studies including cystogram should be considered in case of doubt.

CL Cho *, FRCS Ed (Urol), FHKAM (Surgery)

WKW Chan, FRCS Ed (Urol), FHKAM (Surgery)

RWH Chu, FRCS Ed (Urol), FHKAM (Surgery)

IC Law, FRCS Ed (Urol), FHKAM (Surgery)

Division of Urology, Department of Surgery, Kwong Wah Hospital, Yaumatei, Hong Kong

* Corresponding author: chochaklam@yahoo.com.hk; ccl296@ha.org.hk

\section{References}

1. White SA, Thompson MM, Boyle JR, Bell PR. Extraperitoneal bladder perforation caused by an indwelling urinary catheter. Br J Surg 1994;81:1212.

2. Caoili EM, Cohan RH, Korobkin M, et al. Urinary tract abnormalities: initial experience with multi-detector row CT urography. Radiology 2002;222:353-60.

3. Abadi S, Brook OR, Solomonov E, Fischer D. Misleading positioning of a Foley catheter balloon. Br J Radiol 2006;79:175-6. 